\title{
Flow Injection Analysis of Ammonia and Sulfur Dioxide with Piezoelectric Detection
}

\author{
Tadeusz Krawczynski vel KrawCZYK and Marek Trojanowicz \\ Department of Chemistry, University of Warsaw, Pasteura 1, 02-093 Warsaw, Poland
}

\begin{abstract}
As crystal-coating materials used for ammonia sensors, hydrochlorides of pyridoxine, glutamic acid, histidine, methionine, alanine and cysteine were examined. By using the first three of them a satisfactory detection of ammonia in the wide range from $1 \mathrm{ppb}$ to $10^{3} \mathrm{ppm}$ could be obtained. Under optimized conditions the lifetime of a histidine hydrochloride-based sensor can be extended to 1 month, whereas for a pyridoxine hydrochloride-based detector, due to the possibility of regeneration, even up to 4 months is possible. Among several compounds examined as coating substances for sulfur dioxide detection, tripropylamine and tridodecylamine can be utilized only for the determination of a large concentration of $\mathrm{SO}_{2}$, above $0.1 \% \mathrm{v} / \mathrm{v} . \quad N, N, N^{\prime}, N^{\prime}$-tetrakis(2-hydroxyethyl)ethylenediamine (EDTE) and $N, N, N^{\prime}, N^{\prime}$-tetrakis(2-hydroxypropyl)ethylenediamine (EDTP) can be employed for a much lower range of $\mathrm{SO}_{2}$ concentrations, namely 1 to 1000 and 0.01 to $1000 \mathrm{ppm}$ for EDTE and EDTP, respectively. A lifetime study of $\mathrm{SO}_{2}$ detectors has shown that although an EDTP-based $\mathrm{SO}_{2}$ sensor can be used for 2 months, its detectability gradually deteriorates. Upon using an EDTP-based sensor some disadvantages of serial syringe dilution for the preparation of gas standard mixtures were noted. For a comparison, an alternative procedure employing gas-permeable tubing was proposed.
\end{abstract}

Keywords Flow injection analysis, piezoelectric detection, sulfur dioxide, ammonia

Sulfur dioxide is presently a very common pollutant of the atmospheric air, mainly of antropogenic origin; its content is the most often controlled parameter of air pollution. The ammonia present in atmospheric air has both biogenic as well as antropogenic origins. Although it is not so harmful for the environment, it plays an important role in the formation and stabilization of harmful aerosols.

In addition to numerous other analytical methods developed and used routinely for the determination of those species, piezoelectric detection has also already been applied, though none of them has been utilized for the routine control of air pollution. Therefore, further attempts to optimize and improve detection seem to be desirable.

The most important step in developing a piezoelectric sensor for a given species is to find a suitable non-volatile coating material which would ensure the reversible and selective sorption of the molecules to be detected. For ammonia-sensing detectors polyalkyl glycols UCON-75$\mathrm{H}-90.000$ and UCON-B-300X $\mathrm{X}^{1}$, capiscum annum preparations as well as mixtures of ascorbic acid with silver nitrate $^{2}$ and pyridoxine and glutamic acid hydrochlorides $^{3}$ have been used as coating materials. For the latter two species, the best results were reported. Several studies concerning the improvemenmt of the lifetime of ammonia-sensitive detectors ${ }^{4,5}$ and an advanced computer-based elimination of interference in a multidetector system ${ }^{6}$ can also be found in the literature.
More extensive literature is available concerning piezoelectric sensors for sulfur dioxide. A search for a suitable coating material has started from non-selective Carbowax 20M, assuming the separation of $\mathrm{SO}_{2}$ from other components of the sample by gas chromatography. ${ }^{7,8}$ In further studies, SDM polymer9,10, triethanolamine and ethylenedinitrilotetraethanol ${ }^{1-13}$ as well as ethylenedinitrilotetrapropanol-2 $2^{14,15}$ have been employed as much more sensitive coating materials. The last one exhibited a very low detectability $(10 \mathrm{ppm})$ and a wide (over 3 orders of magnitude) range of linear response to $\mathrm{SO}_{2}$. For a measuring system equipped with such an $\mathrm{SO}_{2}$ sensor, a microcomputer-controlled system used to eliminate the effect of temperature changes was recently developed. ${ }^{16}$ The use of some organophosphine transition metal complexes as coating materials provided a much poorer detectability of $\mathrm{SO}_{2}$, and a narrower concentration range of detection. ${ }^{17}$ An indirect piezoelectric method proposed for $\mathrm{SO}_{2}$ determination was based on the reaction of $\mathrm{SO}_{2}$ with mercury(I) ion, in which a stoichiometric amount of metallic mercury was produced, forming amalgam with gold electrodes of the piezoelectric crystal. ${ }^{18}$

The aim of this work was to optimize the ammonia and sulfur dioxide piezoelectric sensors for use in a flow injection system with a gaseous carrier employing either reported earlier or not used before coatings. Results concerning a general study on factors affecting the piezoelectric detector response have already been reported. ${ }^{19}$ 


\section{Experimental}

\section{Instrumentation}

Flow-through detectors were equipped with $13 \mathrm{~mm}$ diameter $\alpha$-quartz A-T cut crystals of $9 \mathrm{MHz}$ fundamental frequency with gold electrodes from Universal Sensors (New Orleanes, LA, USA), or $6.5 \mathrm{~mm}$ diameter quartz crystals with silver electrodes of fundamental frequency of $8.9 \mathrm{MHz}$ from Omig (Warsaw, Poland) oscillated by the use of a laboratory-made highfrequency generator. The oscillation frequency was measured using a digital frequency counter (KZ2026A) from Zopan (Warsaw, Poland), and recorded with an analog strip chart recorder (TZ4100) from Laboratorni Pristroje (Praha, Czechoslovakia) via a home-made digital-to-analog converter. The flow-through detector design was the same as that reported by Karmarkar and Guilbault. ${ }^{14}$ Air as a carrier gas was pumped with a membrane pump through a column with a drying agent and granulated charcoal. The flow rate of the carrier gas was controlled with a flow meter placed downstream of the detector. A septum injection valve was placed between the carrier-purifying column and the detector kept in a $400 \mathrm{ml}$ air-thermostated chamber (TH-24) from DHN (Warsaw, Poland). A schematic diagram of the system is shown in Fig. 1.

\section{Reagents}

The following chemicals were used as coating materials in the present study: tripropylamine (TPA) from Fluka (Buchs, Switzerland), tridodecylamine (TDA) from

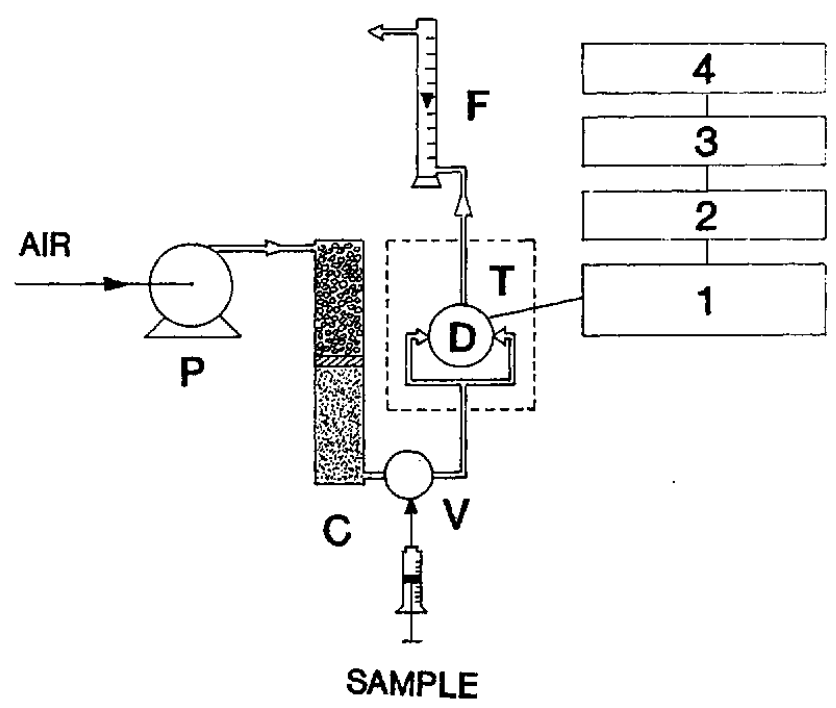

Fig. 1 Schematic diagram of the instrumental set-up used for the flow injection analysis in gaseous phase with piezoelectric detectors: $P$, membrane pump; $\mathrm{C}$, purifying and drying column; $\mathrm{V}$, septum injection valve; $\mathrm{D}$, flow through piezoelectric detector; $T$, thermostated chamber; $F$, flow meter; 1 , high frequency generator; 2 , frequency counter; 3 , D/A converter; 4 , strip chart recorder.
Lancaster Synthesis (Morecambe, England), $N, N, N^{\prime}, N^{\top}-$ tetrakis(2-hydroxyethyl)ethylenediamine (EDTE) from Fluka, $N, N, N, N^{r}$-tetrakis(2-hydroxypropyl)ethylenediamine (EDTP) from Sigma (St. Louis, MO, USA), glutamic acid hydrochloride $(\mathrm{GaHCl})$ from Aldrich (Gillingham, England), pyridoxine hydrochloride ( $\mathrm{PHCl}$ ) from Sigma, L-histidine hydrochloride (His HCl) was prepared by reaction of $\mathrm{L}$-histidine from Sigma with hydrochloric acid, L-methionine, D,L-cysteine and $\beta$ alanine hydrochlorides were prepared by the reaction of amino acids purchased from Reanal (Budapest, Hungary).

\section{Results and Discussion}

Optimization of the oscillator coating for ammonia detection

During this study, the coating materials already examined by other authors, as well as several other compounds, were considered as coating substances for a piezoelectric ammonia sensor for the flow injection system.

\section{Pyridoxine hydrochloride}

As mentioned above, pyridoxine hydrochloride has been successfully used for an ammonia detector. ${ }^{3}$ The aim of this study was to investigate several factors, which were not studied in detail for detectors with a coating.

The two types of quartz oscillators used in the present study differed regarding the diameter of the quartz plate, and in the material of the metal electrodes on both sides of the crystal. Gold electrodes were used in oscillators from Universal Sensors and silver ones from Omig. As listed in Table 1, the functional characteristics of ammonia sensors with the same amount of coating $\mathrm{PHCl}$ are similar. These data were obtained for freshly coated oscillators. However, depending on the frequency of the detector used for measurements and its storage, its characteristics change. Practically, in 10-day tests of an oscillator from Universal Sensors, the ammonia sensor can be used for measurements in the range from $1 \mathrm{ppb}$ to $10^{3} \mathrm{ppm}$ ammonia (Table 2). One example of a flow injection recording is given in Fig. 2. Once-a-day calibration is sufficient. The dynamic characteristics of the

Table 1 Characteristics of piezoelectric ammonia sensors freshly coated with $\mathrm{PHCl}$ in a flow injection sytem with air as a carrier gas at a flow rate of $50 \mathrm{ml} / \mathrm{min}$

\begin{tabular}{|c|c|c|c|}
\hline $\begin{array}{c}\text { Amount of coating/ } \\
\mathrm{kHz}\end{array}$ & $\begin{array}{l}\text { Linear range }{ }^{\mathrm{a}}, \\
\log \left[\mathrm{NH}_{3}, \mathrm{ppb}\right]\end{array}$ & Slope $^{a}$ & $r^{\mathrm{a}}$ \\
\hline \multicolumn{4}{|l|}{ Universal Sensors } \\
\hline 21.9 & $1-5$ & 0.116 & 0.9899 \\
\hline \multicolumn{4}{|l|}{ Omig } \\
\hline 20.4 & $1.5-5$ & 0.095 & 0.9821 \\
\hline
\end{tabular}

Injected sample volume, $10 \mathrm{ml}$.

a. For calibration plots in logarithmic coordinates. 
Table 2 Changes of the functional characteristics of a piezoelectric ammonia sensor made of Universal Sensors quartz oscillators with a $\mathrm{PHCl}$ coating in the flow injection system

\begin{tabular}{cccc}
\hline $\begin{array}{c}\text { Consecutive day } \\
\text { of operation }\end{array}$ & $\begin{array}{c}\text { Linear range } \\
\log \left[\mathrm{NH}_{3}, \mathrm{ppb}\right]\end{array}$ & Slope $^{\mathrm{a}}$ & $r^{\mathrm{a}}$ \\
\hline 1 & $1-5$ & 0.145 & 0.9912 \\
2 & $0-6$ & 0.230 & 0.9912 \\
3 & $1-6$ & 0.162 & 0.9972 \\
8 & $0-6$ & 0.162 & 0.9844 \\
9 & $1-6$ & 0.189 & 0.9930 \\
10 & $0-6$ & 0.143 & 0.9906 \\
\hline
\end{tabular}

The experimental parameters are as in Table 1.

a. For calibration plots in logarithmic coordinates.

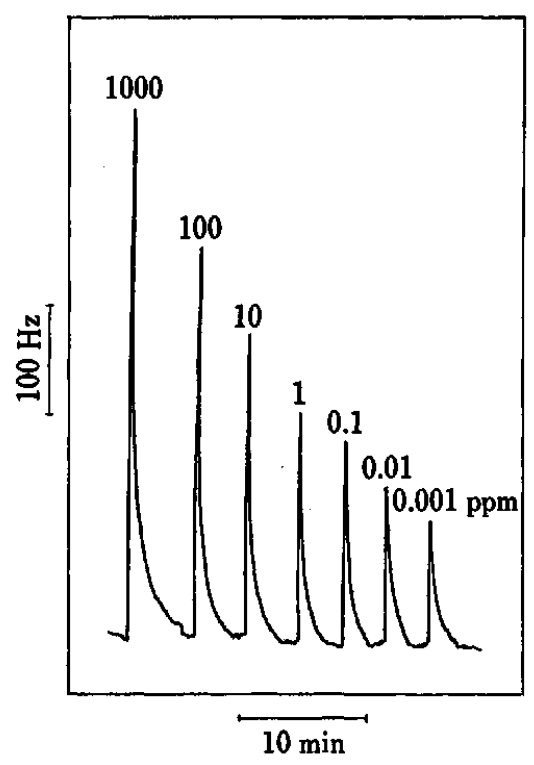

Fig. 2 Flow injection response of the piezoelectric ammonia sensor with $\mathrm{PHCl}$ coating $(12.3 \mathrm{kHz})$ obtained in the system with air as the carrier gas at the flow rate of $50 \mathrm{ml} / \mathrm{min}$. Injection sample volume, $10 \mathrm{ml}$; temperature, $25^{\circ} \mathrm{C}$.

response do not vary significantly over the entire range of the measured concentrations. As shown in Table 3, the sensitivity of the flow injection detection, expressed by the slope of the calibration plot, does not depend essentially on the amount of coating material applied to the oscillator.

A similar examination of an ammonia sensor made with an oscillator from Omig showed much greater changes in the detector characteristics within 4 months and a systematic loss of detectability. After 2 months the lower end of the linear part of the calibration plot shifted up to $100 \mathrm{ppb}$ of ammonia.

The experimental data obtained for two different types of quartz oscillators prove that $\mathrm{PHCl}$ is a satisfactory coating material for an ammonia sensor. However, such a low detectability as $0.1 \mathrm{ppb}$ reported earlier ${ }^{3}$ was not confirmed. The relatively stable response of a
Table 3 Effect of the amount of $\mathrm{PHCl}$ applied to a quartz oscillator on the sensitivity of a piezoelectric ammonia sensor

\begin{tabular}{cc}
\hline Amount of $\mathrm{PHCl}$ used $/ \mathrm{kHz}$ & $\begin{array}{c}\text { Slope of logarithmic } \\
\text { calibration plots }\end{array}$ \\
\hline 21.9 & 0.116 \\
15.5 & 0.126 \\
10.1 & 0.127 \\
\hline
\end{tabular}

The experimental parameters are as in Table 1.

PHCl-based ammonia sensor can be expected for about 10 days.

\section{L-Glutamic acid hydrochloride}

The use of $\mathrm{GAHCl}$ as a coating material was also reported for an ammonia sensor with a working range from $1 \mathrm{ppb}$ to $10 \mathrm{ppm} .^{3}$ Experimental results showed a linear response in logarithmic coordinates, even up to $10^{3} \mathrm{ppm}$. However, for an optimum distribution of the coating material on the oscillator electrodes surface the signal magnitude for $1 \mathrm{ppm}$ was four-times smaller than that reported earlier. ${ }^{3}$ The dynamic characteristics of the GAHCl-based ammonia sensor are worse than that obtained for $\mathrm{PHCl}$-based sensor, due to a slower desorption of ammonia from the coating layer. The irreversible sorption of a certain amount of ammonia from injected samples causes a much faster loss of the sensitivity of detection within 5 days. Storing the $\mathrm{GAHCl}$ sensor in a stream of flowing carrier gas was not helpful.

Changing $\mathrm{GAHCl}$ into a sulfate derivative of $\mathrm{L}-$ glutamic acid improves slightly the lifetime of the sensor. However, at the same time, such parameters as the signal magnitude, sensitivity of detection, and the detectability deteriorated. The lower end of the linear range of calibration was $1 \mathrm{ppm}$ of ammonia.

\section{L-Histidine hydrochloride}

The hydrochlorides of several other amino acids, such as L-histidine, L-methionine, D,L-cysteine and $\beta$-alanine, were also examined as coating materials for a piezoelectric ammonia sensor. Satisfactory results were obtained practically for only L-histidine hydrochloride ( $\mathrm{HisHCl})$. For other coating materials of this type, the signal magnitude was too small (methionine, cysteine, alanine), irreversible sorption of ammonia was observed (methionine) or the base-line frequency was too unstable (cysteine).

The maximum amount of $\mathrm{His} \mathrm{HCl}$ coating possible to apply without any loss of the crystal oscillations was of about $15 \mathrm{kHz}$. For a freshly prepared ammonia sensor the signal magnitude was about $800 \mathrm{~Hz}$; this was much larger than that for optimized $\mathrm{PHCl}$ - and $\mathrm{GAHCl}$-based detectors. Although a systematic decrease of the signal magnitude in time was observed, satisfactory sensitivity and detectability was maintained for 1 month. After 


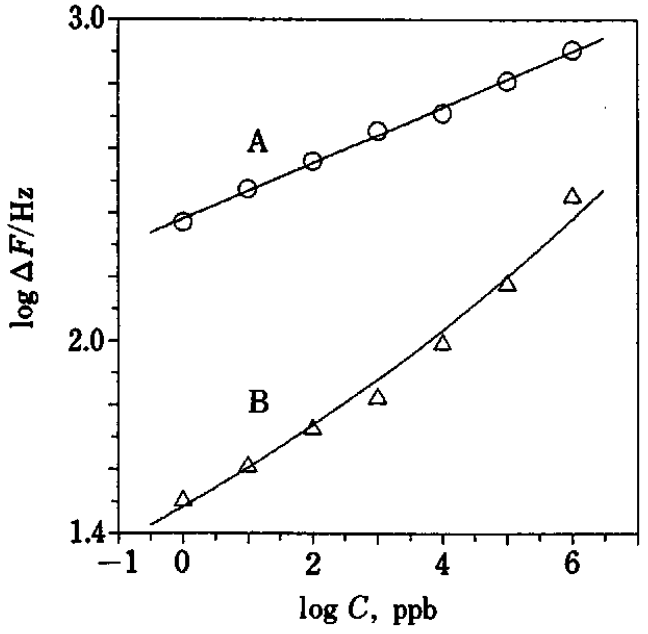

Fig. 3 Calibration plots obtained for the flow injection detection of ammonia using freshly coated (A) and 3 weeks old (B) HisHCl-based sensor in the system with air as the carrier gas at the flow rate of $50 \mathrm{ml} / \mathrm{min}$. Injected sample volume, $10 \mathrm{ml}$; temperature, $25^{\circ} \mathrm{C}$.

about 1 week, a disadvantageous loss of the linearity of calibration plots was observed. Figure 3 shows examples of the calibration plots obtained for a freshly coated quartz crystal, and after 3 weeks of use of the sensor in flow measurements. The $\mathrm{HisHCl}$ ammonia sensor can be used for flow injection detection of ammonia over the range from $1 \mathrm{ppb}$ to $10^{3} \mathrm{ppm}$ with satisfactory precision $(\mathrm{RSD}<5 \%)$. Its dynamic property is similar to that of the $\mathrm{PHCl}$ sensor, except for a more extended lifetime. The observed decrease of the sensitivity does not require more frequent calibration in flow measurements than once a day.

\section{Optimization of crystal coating for sulfur dioxide detection}

In optimizing the coating material for an $\mathrm{SO}_{2}$ sensor, several substances were examined, which were used earlier by other authors. However, they were not critically compared in the same measuring system. As shown below, they can be used for the preparation of $\mathrm{SO}_{2}$ detectors with very different characteristics.

\section{Tri-n-alkylamines}

Tripropylamine (TPA) and tridodecylamine (TDA) were reported by Frechette and Fasching ${ }^{10}$ as coating materials for an $\mathrm{SO}_{2}$ piezoelectric sensor exhibiting the largest signals obtained for injections of only pure sulfur dioxide. In this flow injection system, even a larger signal magnitude was observed. The frequency change for the injections of pure $\mathrm{SO}_{2}$ was $350 \mathrm{~Hz}$ (for a coating amount of $7.1 \mathrm{kHz}$ ), in comparison to $225 \mathrm{~Hz}$ reported earlier for TPA. 9 Both of the amines examined were the most suitable as coating materials for detecting large concentrations of $\mathrm{SO}_{2}$. For a TPA-coated oscillator, a linear dependence of the frequency change within the range from 1 to $100 \% \mathrm{v} / \mathrm{v}$ was obtained with the follow- ing parameters of the calibration plot:

$$
\Delta F=3.5 C+3.2 \quad(r=0.998 \text { for } n=11) .
$$

Over almost the entire range of the examined $\mathrm{SO}_{2}$ concentrations, very good dynamic sensor properties were observed, with about $80 \%$ desorption within $10-15 \mathrm{~s}$.

A small drift in the base-line during flow measurements for several initial days after the coating was applied can be attributed to the relatively high volatility of TPA; this, however, does not influence the detection precision, which was estimated as being 0.5 to $5 \%$, depending on the concentration. The lifetime of the TPA-based $\mathrm{SO}_{2}$ sensor was estimated as being about 1 to 2 weeks.

Although a slightly different behavior was observed for the TDA-based sensor, it is also most useful for measurements of high $\mathrm{SO}_{2}$ concentrations. The calibration plots obtained for flow injection measurements exhibit three linear parts in the concentration ranges (10 to $100 \%, 1$ to $10 \%$ and 0.1 to $1 \%$ ) of different slopes (32, 10 and $2.7 \mathrm{~Hz} / \%$, respectively). Due to a smaller volatility, the change in the base-line frequency in the flow system was not practically observed, and the desorption rate was higher than that for the TPA coated sensor. The precision and lifetime, however, were similar in the case of both of the examined amines.

\section{Ethylenedinitrilotetraalcohols}

The EDTE and EDTP used in this study for a comparison with trialkylamines showed a much better detectability of $\mathrm{SO}_{2}$ sensors, but did not differ very much, due to very similar structure as well as physico-chemical properties. The calibration plots obtained in flow injection measurements are linear over the same concentrations range from 0.1 to $10^{3} \mathrm{ppm}$ in logarithmic coordinates. For several EDTP-coated crystals the

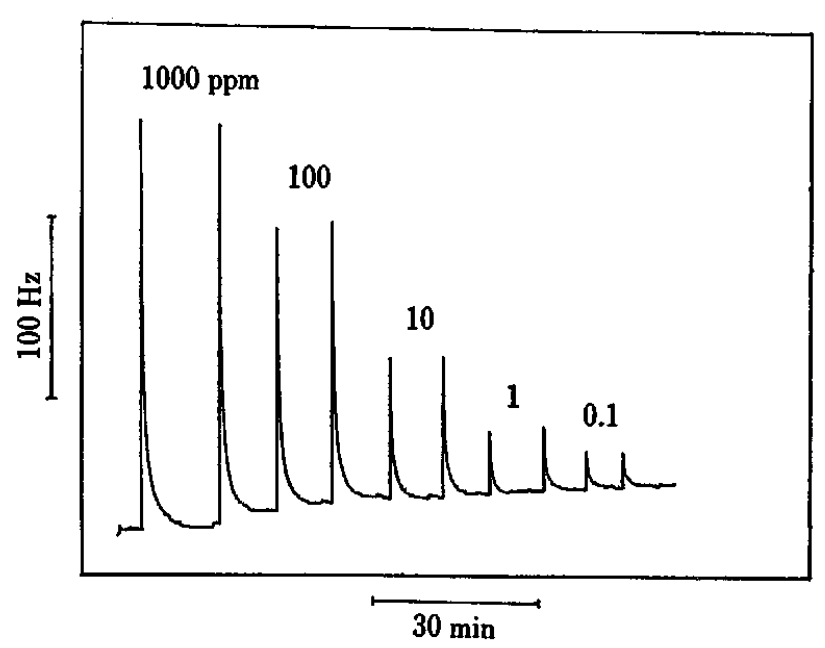

Fig. 4 Flow injection response of the piezoelectric $\mathrm{SO}_{2}$ sensor with EDTP coating $(9.3 \mathrm{kHz})$ obtained in the system with air as the carrier gas at the flow rate of $50 \mathrm{ml} / \mathrm{min}$. Injected sample volume, $10 \mathrm{ml}$; temperature, $25^{\circ} \mathrm{C}$. 
linear response extended to $10 \mathrm{ppb}$ and, sporadicly, even down to $1 \mathrm{ppb}$, six orders of magnitude of $\mathrm{SO}_{2}$ detection. The absolute values of the frequency change for the EDTE coating were larger, due to stronger $\mathrm{SO}_{2}$ sorption. This, however, was also associated with a slower desorption of $\mathrm{SO}_{2}$ from the coating material layer. For EDTP over the entire range of measured concentrations, the desorption interval in the flow injection measurement did not exceed $5 \mathrm{~min}$ (Fig. 4). The precision of the flow injection measurements with both coating materials examined was better than $10 \%$ for an $\mathrm{SO}_{2}$ concentration below $1 \mathrm{ppm}$, and about $5 \%$ for larger concentrations of injected samples. Both detectors exhibited a satisfactory stable base-line frequency in flow injection measurements.

Sulfur dioxide sensors with an EDTP coating also exhibited a very stable response within an almost twomonth period of time (Table 4). After two weeks only small losses of the signal magnitude and detectability were observed.

\section{Comparison of flow injection and continuous flow measure- ments with piezoelectric detection}

Injection measurements with piezoelectric detectors are very rapid and convenient for the detection of ammonia ${ }^{1-3}$ or sulfur dioxide ${ }^{14,15}$ when discrete sampling of analyzed gaseous mixture can be applied. However, the sensitivity of such measurements is usually much lower than that expected from the Sauerbrey equation. This is attributed to at least two basic reasons. The first one is the transient character of the detector response. Due to the relatively high flow rate used, and the small injected sample volume, the sorption system is far from equilibrium conditions, and the magnitude of the transient response substantially depends on the concentration. The second source of that deviation may be found in one disadvantage of the syringe dilution method for the preparation of standard gas mixtures, as discussed by Beitnes and Schroder. ${ }^{20}$ Due to the adsorption of analyzed species on the walls of the syringe used for multiple dilution, the real concentration in an

Table 4 Changes of the functional characteristics of a piezoelectric sulfur dioxide sensor with EDTP coating in the flow injection system with air as a carrier gas at flow rate of $50 \mathrm{ml} / \mathrm{min}$

\begin{tabular}{cccc}
\hline $\begin{array}{c}\text { Consecutive day } \\
\text { of operation }\end{array}$ & $\begin{array}{c}\text { Base-line } \\
\text { frequency/MHz }\end{array}$ & $\begin{array}{c}\text { Slope } \\
\text { a }\end{array}$ & $\begin{array}{c}\text { Lower limit of } \\
\text { linear response, } \\
\text { ppm }\end{array}$ \\
\hline 1 & 8.9913 & 0.268 & 0.01 \\
3 & 8.9915 & 0.258 & 0.01 \\
15 & 8.9911 & 0.222 & 0.1 \\
16 & 8.9917 & 0.237 & 0.1 \\
26 & 8.9924 & 0.240 & 0.1 \\
52 & 8.9929 & 0.266 & 1.0 \\
\hline
\end{tabular}

Injected sample volume, $10 \mathrm{ml}$; temperature, $25^{\circ} \mathrm{C}$.

a. For calibration plots in logarithmic coordinates. injected sample is larger than the calculated value, especially when several dilutions are performed. This significantly influences the course of the calibration plot, as illustrated in Fig. 5, where the same frequency changes are plotted $v s$. the concentration calculated from the number of dilutions (curve A), and measured spectrophotometrically with the pararosaniline method after absorption in the solution (curve B). Obviously, the deviation of the observed slopes depends on the extent of $\mathrm{SO}_{2}$ adsorption on the syringe walls, which is mainly dependent on the type of syringe used. In practice, however, when all operations are performed reproducibly, those effects of the transient character of the response and syringe dilution can yield satisfactory results.

Flow measurements of gaseous species with piezoelectric detection can also be carried out in a continuousflow system, which can be standardized using porous Teflon gas-permeable tubing (Fig. 6). $\mathrm{SO}_{2}$ is generated

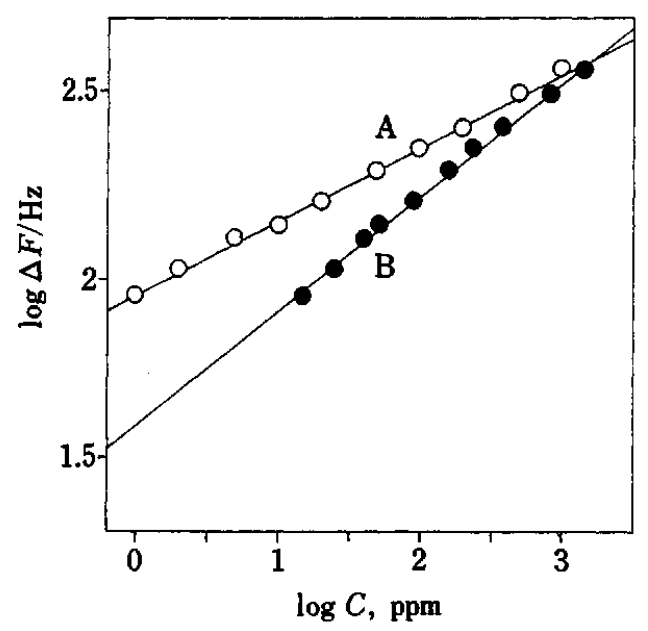

Fig. 5 Calibration plots obtained in standard mixtures of concentrations calculated according to the number of dilutions (A) and to spectrophotometric determinations (B) for the flow injection detection of $\mathrm{SO}_{2}$ using the EDTP coated detector.

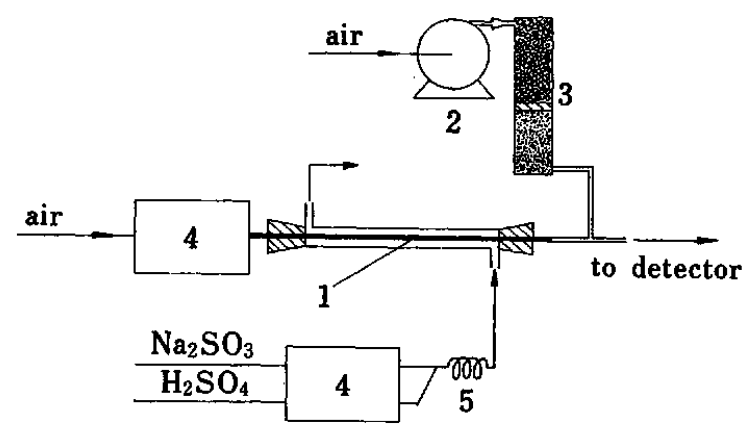

Fig. 6 Schematic diagram of the continuous-flow system used for the standardization of a piezoelectric $\mathrm{SO}_{2}$ detector using porous PTFE gas permeable tubing (1). (2), membrane pump for air; (3), air purifying column; (4) peristaltic pump; (5), mixing coil. 
to the stream of air from a mixture of $10 \%$ sodium sulfite and $6 \mathrm{M}$ sulfuric acid; its concentration depends on the flow rate of air delivered with the pump. This stream is then merged with another stream of air in order to produce a total flow rate of $50 \mathrm{ml} / \mathrm{min}$ through the detector. The content of $\mathrm{SO}_{2}$ for different flow rates of the air stream flowing through the porous tubing was calibrated using a spectrophotometric method. The desorption of $\mathrm{SO}_{2}$ from the coating material of the piezoelectric detector was obtained when a sodium sulfite solution was replaced by distilled water. An example of the signals recorded in such a system is shown in Fig. 7 for an EDTP coated crystal. Besides a much slower total response of the system, a substantial difference was found in the calibration plot, compared to that for a flow injection system with the same piezoelectric detector (Fig. 8). The obtained calibration plot was linear $v s$. the concentration of $\mathrm{SO}_{2}$ in flowing gas mixtures with a correlation coefficient of 0.9984 . However, the precision of the response was worse than that obtained in flow injection measurements. In order to shorten the

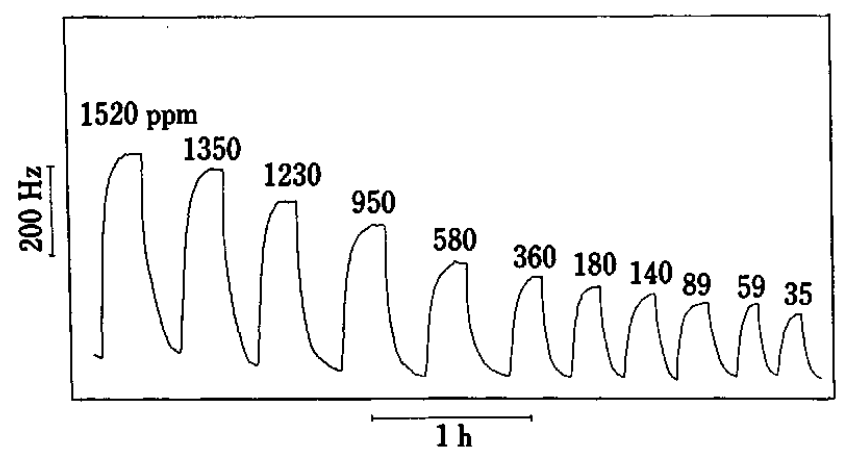

Fig. 7 Responses of an EDTP-coated $\mathrm{SO}_{2}$ piezoelectric detector obtained in the continuous-flow system shown in Fig. 6.

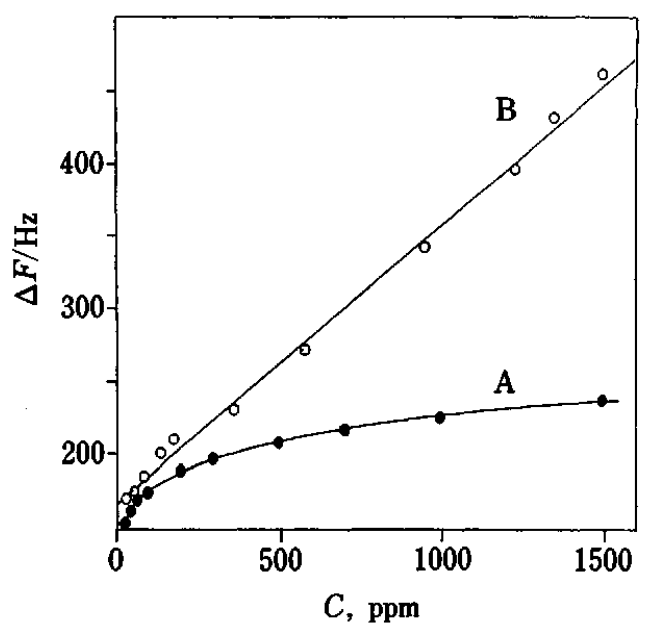

Fig. 8 Calibration plots for an EDTP-coated $\mathrm{SO}_{2}$ detector obtained in the flow injection (A) and continuous flow (B) system. desorption time the flow rate was increased up to $300 \mathrm{ml} /$ min. The total time interval for one measurement was about $30 \mathrm{~min}$. This can be considered as being a good illustration of the advantages of a flow injection measurement system for determining gaseous species with piezoelectric detectors.

In conclusion, this study on the optimization of piezoelectric detection of ammonia in several cases did not confirm earlier reports. For $\mathrm{PHCl}$ used as a coating material the linear response of the detector was found over the range from $1 \mathrm{ppb}$ to $10^{3} \mathrm{ppm}$, instead of the earlier reported $0.01 \mathrm{ppb}$ to $1 \mathrm{ppm} .^{3}$ It was also found that the sensors with a $\mathrm{PHCl}$ coating show a significantly extended lifetime, due to the possibility of regeneration. Such earlier reported sensors exhibited a very fast loss of sensitivity. ${ }^{4}$ For GAHCl-coated detectors, a much broader range of response ( $1 \mathrm{ppb}$ to $10^{3} \mathrm{ppm}$ ) was found, than that described by other authors. ${ }^{3}$ Satisfactory results were also obtained for the $\mathrm{HisHCl}$ coated sensor for the detection of ammonia.

For piezoelectric $\mathrm{SO}_{2}$ sensors, tri- $n$-alkylamines can be employed for detecting high $\mathrm{SO}_{2}$ concentrations $(>0.1 \%$ $\mathrm{v} / \mathrm{v}$ ), whereas EDTE and, especially, EDTP can be used over a wide range of concentrations, at least from 0.1 to $10^{3} \mathrm{ppm}$. Some new information concerning the properties of those sensors obtained in this study include, among others, an examination of the full possibilities of TPA and TDA use for the determination of sulfur dioxide, as well as the long-time behavior of EDTP coatings not documented in the literature. The latter has shown that this coating can be used, at least, within 2 months without any significant loss of the sensitivity, expressed as the slope of the calibration plot, and practically with the same linearity range from 0.1 to $10^{3} \mathrm{ppm}$. However, the signal magnitude decreases after few days to about $50 \%$ of the initial value, and then remaining stable.

A comparison of different flow systems with piezoelectric detection carried out during this study has shown some drawbacks of such measurements, such as the transient character of a signal, causing a loss of detection sensitivity, as well as advantages such as fast response and satisfactory precision.

\section{References}

1. K. H. Karmarkar and G. G. Guilbault, Anal. Chim. Acta, 75, 111 (1975).

2. L. M. Webber and G. G. Guilbault, Anal. Chem., 48, 2244 (1976).

3. J. Hlavay and G. G. Guilbault, Anal. Chem., 50, 1044 (1978).

4. G. J. Moody, J. D. R. Thomas and M. A. Yarmo, Anal. Chim. Acta, 155, 225 (1983).

5. C. S. I. Lai, G. J. Moody and J. D. R. Thomas, Anal. Proc., 22, 11 (1985).

6. S. M. Fraser, T. E. Edmonds and T. S. West, Analyst [London], 111, 1183 (1986). 
7. A. Lopez-Roman and G. G. Guilbault, Anal. Lett., 5, 225 (1972).

8. M. Janghorbani and H. Freund, Anal. Chem., 45, 325 (1973).

9. M. W. Frechette, J. L. Fasching and D. M. Rosie, Anal. Chem., 45, 1765 (1973).

10. M. W. Frechette and J. L. Fasching, Environ. Sci. Technol., 7, 1135 (1973) .

11. J. L. Cheney and J. B. Homolya, Anal. Lett., 8, 175 (1975).

12. J. L. Cheney and J. B. Homolya, Sci. Total Environ., 5, 69 (1976).

13. J. Cheney, T. Norwood and J. Homolya, Anal. Lett., 9, 361 (1976).

14. K. H. Karmarkar and G. G. Guilbault, Anal. Chim. Acta, 71, 419 (1974).
15. K. H. Karmarkar, L. W. Webber and G. G. Guilbault, Anal. Chim. Acta, 81, 265 (1976).

16. R. D. Snook and P. E. Zaft, Analyst [London], 114, 149 (1989).

17. R. L. Cook, R. C. Macduff and A. F. Sammels, Anal. Chim. Acta, 217, 101 (1989).

18. A. A. Suleiman and G. G. Guilbault, Anal. Chem., 56, 2964 (1984).

19. M. Trojanowicz and T. Krawczynski vel Krawczyk, Sensors Actuators, in press.

20. H. Beitnes and K. Schroder, Anal. Chim. Acta, 158, 57 (1984).

(Received December 22, 1991) (Accepted March 25, 1992) 